\title{
Mixed Astrocytoma-Ependymoma
}

National Cancer Institute

\section{Source}

National Cancer Institute. Mixed Astrocytoma-Ependymoma. NCI Thesaurus. Code C8271.

A tumor of mixed cell type with astrocytic components as well as ependymoma components. 